\title{
How does the PRIDE theory describe leadership and organisation that enhances vocational education teachers' (VET) enthusiasm? An analysis of enthusiastic Finnish VET-teachers' perceptions
}

\author{
Sanna Wenström \\ Satu Uusiautti \\ Kaarina Määttä
}

\begin{abstract}
The purpose of this research was to analyse vocational education teachers' (VET) perceptions of enthusiasm at work. The analysis leaned on positive organisational theory and an index called PRIDE. Finnish VETs $(N=15)$ who described themselves as enthusiastic teachers were interviewed with a themed interview method. The analysis followed the principles of qualitative content analysis. The data were categorised in a theory-based manner into the elements of PRIDE theory: positive practices, relationship enhancement, individual attributes, deviant leadership, and emotional well-being. According to the findings, the elements of PRIDE appeared interconnected in a manner that could be enhanced through leadership and organisation of work. Three themes appeared common to all elements: opportunities for development and to develop work, recognition and use of strengths and potential, and enhancement of interaction and collaboration. The research brought important information about how VETs could cope with the current changing work, and maintain their enthusiasm during the reform process of vocational education taking place in Finland. In addition, suggestions were made on how to lead and enhance teacher enthusiasm as a part of renewing vocational teaching.
\end{abstract}

Keywords: positive organisational scholarship, positive leadership, teacher, enthusiasm, engagement, VET 


\section{Introduction}

Positive organisational theory is interested in positive phenomena and processes taking place in organisations (Cameron 2013). One example of these phenomena is enthusiasm experienced by employees. Enthusiasm is seen as a part of work engagement, being its affective element and manifestation (Kunter \& Holzberg 2014; Macey \& Schneider 2008; Schaufeli 2018; Schaufeli, Salanova, González-Romá \& Bakker 2002). In research, work engagement and enthusiasm are often connected with organisational productivity and quality (e.g., Demerouti \& Cropanzano 2010; Schaufeli 2018; Thompson, Lemmon, \& Walter 2015; Xanthopoulou, Bakker, Demerouti, \& Schaufeli 2009). When it comes to educational organisation, teachers' enthusiasm has been noted to be connected with students' academic performance and motivation (Keller, Neumann, \& Fisher 2013; Kunter et al. 2013; Patrick, Hisley, \& Kempler 2000) as well as teaching quality (Frenzel et al. 2009; Kunter et al. 2011, 2013). These findings appear promising when thinking about the current situation in Finnish vocational education. While during the ongoing big educational reform resources for vocational education have decreased, education is still expected to be more productive, efficient and of higher quality (Minedu 2017; see also Owens, Baker, McDaniel Sumpter \& Cameron 2016). One assumption is that if VETs could maintain enthusiasm, if they could be even more enthusiastic about their work and show enhanced work engagement, the goals of the reform could be better achieved.

The reform takes vocational education into a competence-based direction. Simultaneously, it changes and expands VETs' work and creates new demands on them. Teachers are expected to work creatively by supporting students' individual needs, and in collaboration with various networks and work life (Minedu 2017; see also Vähäsantanen \& Eteläpelto 2011; Vähäsantanen, Saarinen \& Eteläpelto 2010). The new approach necessitates VETs' willingness to renew their way of working and develop their own expertise. These elements are an important part of teachers' enthusiasm: enthusiastic teachers are interested in developing their work and expertise, and are willing to make the effort in their job (Kunter \& Holzberg 2014; Macey \& Schneider 2008; Wenström, Uusiautti \& Määttä 2018). Furthermore, they show proactivity during in the changing work (Lam, Cheng \& Choy 2010; Macey \& Schneider 2008). Our assumption is that by enhancing enthusiasm in VETs, it would be possible to strengthen the development of teaching according to the idea of the reform.

Organizational factors, including leadership, influence teachers' enthusiasm (Wenström et al. 2018; see also Leithwood, Harris, \& Hopkins 2008; Thoonen et al. 2011). Therefore, PRIDE can offer a useful way of analysing enthusiasm. In this research, our purpose was to analyse what kind of leadership and organisations enhance enthusiasm in VETs, according to their own perceptions. By using PRIDE theory, this research provides a new and positive viewpoint on the reform of vocational education and VETs' enthusiasm.

It is reasonable to assume that positive leadership and organisational culture may enhance enthusiasm, well-being and success at work, that includes expertise and ability to work with various people: and that requires constant learning and renewal (Cheung 2014; Davis 2013; Fredrickson \& Dutton 2008; Geue 2018; Salmi, Perttula, \& Syväjärvi 2014). Therefore, this research also contributes to the research of vocational education organisations and leadership (Beverborg, Sleegers \& van Veen 2015; Bloom, Lemos, Sadun \& Van Reenen 2015; Coates et al. 2013; Jäppinen \& Maunonen-Eskelinen 2011). In addition, the research expands and strengthens research on PRIDE theory (Cheung 2014; Hsiesh \& Shannon 2015; Ince, Jelley \& MacKinnon 2016) and in the field of positive organisational theory in general (Doldor, Silvester \& Atewologun 2017; Rich 2016).

\section{Theoretical background}

The goal of positive organisational research is to recognise and strengthen such practices and methods that make the organisation and its members flourish, be well, and work efficiently (Cameron 2013; Linley, Harrington \& Garcea 2013). One way of analysing these factors is to use the positive organisational index, in other words the PRIDE theory (Cheung 2014, 2015; see also Määttä \& Uusiautti 2018). According to PRIDE, a positive organisation consists of the elements of Positive practices, Relationship enhancement, Individual attributes, Deviant leadership, and Emotional well- 
being. The more evident these elements are, or the higher the positive organisational index is, the better results the organisation is likely to achieve when it comes to the well-being of personnel, productivity, efficiency, and quality. Although PRIDE was developed to quantitative measurements (Cheung 2014), in this research, it is used as a theoretical framework for qualitative analysis of VETs' enthusiasm.

Positive practices mean activities, methods, practices, or resources that help performing well at work and enhance learning, professional growth, and flourishing at the levels of daily work, organisational strategy, leadership, and organisational culture (Cameron, Mora, Leutscher \& Calarco 2011; Cheung 2014). Positive practices are positive because they enhance positive emotions and attitudes and thus support positive atmosphere at work (Hartel \& Ashkanashy 2011). Positive practices are connected with energy, work engagement, and enthusiasm (Albrecht et al. 2015; Geue 2018), which positively influence organisational performance and productivity, too (Albrecht et al. 2015; Cameron 2008; Cameron et al. 2011; Thompson et al. 2015). Examples of positive practices are open communication, clear work organisation and well-defined work contents and goals, opportunities to develop expertise and other positive HR practices (Albrecht et al. 2015; Cheung 2014; Gruman \& Saks 2011).

Relationship enhancement is a central feature of a positive organisation (Mroz \& Quinn 2013), and important vocational education organisations, too. The reform necessitates extremely close collaboration with various networks (Minedu 2017). As in all workplaces, in VETs' organisations, too, collaboration and positive interaction are seen to enhance well-being at work, efficiency, productivity, commitment, and communal learning (Baker \& Dutton 2007; Gittell, 2012; Gittell, Seidner \& Wimbush 2010; Uusiautti 2016). In the school context, teacher collaboration has been noted to enhance students' performance as well (Reeves, Pun, \& Chung 2017). Enthusiasm itself is social, contagious, and interactional by nature (Baker, Cross \& Wooten 2003; Bakker et al. 2006; Geue 2018; Schippers \& Hogenes 2011; Sekerka \& Fredrickson 2013; Stairs\& Galpin 2013; Owens et al. 2016; Wenström et al. 2018). Colloquial support considerably enhances work engagement in teachers (Bakker \& Bal 2010; Lam et al. 2010; Salanova, Bakker \& Llorens 2006).

Individual attributes refers to the appreciation of individual characteristics, differences and various strengths and abilities (Cheung 2014; Stairs \& Galpin 2013). Work engagement specifically emerges from using individual strengths in daily work (Bakker \& Demerouti 2014). Likewise, for organisations, it is important to utilise the whole strength potential of the members of the organisation (Stairs \& Galpin 2013). Focus on strengths and abilities makes it possible to maintain work engagement and enthusiasm under extrinsic pressure and demands for change (Bakker \& Demerouti 2014; Biswas-Diener, Kashdan \& Minhas 2011) because it supports the sense of meaning at work (Stairs \& Galpin 2013; Steger \& Dik 2010; Uusiautti 2016).

Deviant leadership enables the other elements of PRIDE, because leaders and supervisors have the chance to influence organisational practices and resources (Gruman \& Saks 2011; Harter \& Blacksmith 2013; Stairs \& Galpin 2013). Positive leadership promotes positive interaction and collaboration and is, at its best, focused on the employment and development of various strengths and resources (BiswasDiener et al. 2011; Cheung 2014; Geue 2018; Oades et al. 2011). Positive leadership is caring and participatory, and pays attention to emotions (Cheung 2014, Richardson \& West 2013). Positive leadership is the leadership of positive atmosphere, relationships, interaction, and meaning (Cameron 2012; Oades et al. 2011).

Emotional well-being comprises the organisational atmosphere and positive emotions (Cheung 2014; see also Stairs \& Galpin 2013). Enthusiastic employees can positively affect the whole work environment and atmosphere (Mroz \& Quinn 2013), whereas positive work environment supports individual flourishing and work engagement (Geue 2018; Davis 2013). Work engagement and enthusiasm are related to various positive emotions that can also support coping in stressful situations of changing work (Bakker \& Demerouti 2014; Fredrickson \& Joiner 2002; Ong, Bergeman, Bisconti \& Wallace 2006). 


\section{Method}

The research question set for this research was as follows:

How does the PRIDE theory describe leadership and organisation that enhances vocational education teachers' (VET) enthusiasm?

This was qualitative research, seeking to hear the VETs themselves (Cozby \& Bates 2012; Creswell 2014; Ince et al. 2016). In work and organisational research, these kinds of studies want to understand better how people think, feel, and behave at work, and how it can be used to research on motivation, well-being at work, leadership, and organisational change and development (Doldor, Silvester \& Atewologun 2017).

VETs who defined themselves enthusiastic about their work were recruited in this research. This kind of selection of participants resembles purposeful selection, which means that people who are considered to best provide answers to the research question are recruited as the research participants (Creswell 2014; Galletta 2012). This also means that the group of research participants was carefully chosen. An email was sent to Finnish VETs through their networks. Teachers were also approached via social network sites. The recipients were also asked to forward the email to their networks.

Altogether 15 Finnish VETs (11 women and 4 men) participated in the research. They represented six (of 96) vocational education institutions across Finland, 13 different educational units or teams and 11 different vocational fields. VETs were 40-60 years old and had worked as teachers from four to over 30 years. The interviews were conducted in May and April 2018. The interviews lasted from about 30 minutes to 1.5 hours. In this article, the teachers are referred with codes T1-T15.

The interview method was a semi-structured interview (Galletta 2012) that followed the elements of PRIDE (Cheung 2014; Galletta 2012; Hshiesh \& Shannon 2005). First, VETs were asked to freely describe their work and factors they found inspiring in it (Galletta 2012). After that, they were asked more specific questions related to the elements of PRIDE. For example, they were asked to describe positive practices by asking "Could you describe such practices or methods that enhance your enthusiasm at work?" Or, when it came to relationship enhancement, they were to answer the question of "How does the interaction and collaboration in your workplace influence your enthusiasm?" Finally, VETs were given the opportunity to talk about something they found important to the theme (Galletta 2012). Despite the theory-based approach in the interview, the main focus was on experiences the VETs brought up, which allowed new meanings and interpretations to emerge during interviews (Galletta 2012).

The interview data were analysed with the qualitative content analysing method. The theory-led analysis is useful when the existing theory needs to be complemented, extended, or validated (Hshiesh \& Shannon 2005). In the first phase, each interview was categorised into the five elements of PRIDE (Basit 2003; Hshiesh \& Shannon 2005). After that, sub-categories were created and specified under each main category. The sub-categories were data-based. For example, one of the sub-categories of positive practices was "practices enhancing collaboration and interaction".

When it comes to the reliability of the research, it is important to analyse how the interview situations might have affected the data. Did the interviewees genuinely talk about reality, or were the descriptions of enthusiasm merely products of the interview situation (Creswell 2014; Peräkylä 2011)? Qualitative interviews are always created through interaction, in which the researcher is the active partner, and also determines the sequence of the interview unconsciously (Creswell 2014; Galletta 2012). Therefore, it is important that the researcher's prejudices and assumptions are openly reflected (Creswell \& Miller 2000). In this research, the interviewee had wide experience in teaching in vocational education but also profound knowledge of theory and research in the field. However, theory-led content analysis is seen to benefit from expertise and knowledge about the research theme (Hshiesh \& Shannon 2005).

Another critical aspect is whether the data were sufficient. In qualitative research, the quality of data is more important than quantity (Francis et al. 2010). One way of evaluating the saturation of data is to 
assess whether after conducting 10 interviews, three new interviews would not provide new contents (Francis et al. 2010). The data in this research covered 15 interviews. After analysing the first ten, interviews number 11 and 13 provided some new specifications to sub-categories of analysis, but interviews 12, 14, and 15 did not produce new information. Therefore, this criterion was fulfilled (Francis et al. 2010).

Participation in this research was voluntary and confidential. Because interviewees were directly addressed via emails and social network sites, no one except the researcher knows from which vocational education institutions the participants come. This protects the anonymity of the research participants.

\section{Results}

\section{Positive practices}

According to the data, positive practices that enhanced VETs' enthusiasm at work were concrete actions, structures, and processes that also supported the elements of PRIDE. The positive practices could be categorised into practices enhancing (1) development of work and professional growth; (2) interaction and collaboration; and (3) efficient and quality pedagogical work.

Practices enhancing development of work and professional growth included various developmental teams projects that VETs regarded as enabling working with like-minded people who were interested in the same things. Partly these teams and projects were seen as means to enhance careers too because they provided a way of seizing new challenges and expanding one's own work contents.

"- - this project. I mean I just found those people after seven years who are the ones thinking in the same way."(T7)

"I think it is always a sign of a good organisation if it can provide challenges. So you do not have to look for them outside your workplace." (T1)

Main practices enhancing positive interaction and collaboration were team meetings that made it possible for VETs to develop together and share knowledge. Also smaller everyday practices, such as common coffee breaks, or how the offices were arranged, were mentioned as important factors promoting collaboration and innovative work approach. In all, VETs seemed to need informal opportunities to colloquial conversations in addition to formal meetings. New collaboration methods such as innovative core teams or voluntary theme groups were appreciated among VETs.

"We have simultaneously some mentoring and we can discuss our everyday work, what it really is." (T4)

"We have this coffee room there where everyone goes to have coffee. So that helps. You can see the principal and other teachers and leaders at the same time." (T6)

Practices enhancing quality pedagogical action were the opportunity to use positive pedagogy, team learning, work-based learning, and teachers' freedom to plan their own work in general. However, VETs also mentioned that they appreciated well-organised work and functional processes that made it possible for them to focus on their core pedagogical task and use creativity at work. On the other hand, stiff, hierarchical structures and bureaucracy decreased VETs' enthusiasm at work.

"If the practices are something like I have experienced, that you have literally a guide book that states with three sentences that this is how to work, and this lego goes here. It cannot be changed. That destroys all creativity, it destroys all motivation." (T5)

\section{Relationship enhancement}

When it came to the element of relationship enhancement, VETs emphasised positive energy networks and becoming enthusiastic together as well as colloquial support. Specifically emotional support and practical helping at work were regarded as factors that supported enthusiasm. Furthermore, VETs 
described positive collaboration and related conditions of enthusiasm, such as trust, appreciation, responsibility, and openness as well as close relationships between colleagues that surpassed their professional roles.

Positive interaction was described as the basis of enthusiasm. According to VETs, their enthusiasm emerged and strengthened first and foremost in interaction with other people. Enthusiastic teachers reported that they tended to interact actively and participate in networking also beyond their own units or organisations.

"Interaction, it certainly feeds it. - - Having someone to share your enthusiasm or the experience in general. Of course, it strengthens your feeling and takes you again further." (T10)

Similarly, colloquial support was important to VETs' enthusiasm. At its best, teachers were sharing their opinions and feelings about issues or situations (e.g. challenging encounters with students) they had faced.

"We have not needed any outside mentoring. It has been enough to be able to chat together. Quite often after work, we have had little moments to talk about our days." (T4)

One important ingredient of positive interaction and collaboration was familiarisation with others. VETs considered it important to have informal encounters with their colleagues outside work. Long-term coworkers usually knew each other well also in their personal lives. Informal relationships were seen therefore crucial to better interaction and understanding about everyone's way of working.

"Our own group. We have grown together naturally because we are dealing with each other daily. And in this sense our relationships have improved interaction-wise because we have learned to know each other and our ways of reacting and take things." (T1)

\section{Individual attributes}

Organisation and leadership that enable enthusiasm in teachers are based on individual attributes and strengths. In the interview data, themes related to this element of PRIDE were (1) personal development and opportunity develop work; (2) expertise usage and sharing; (3) sense of meaning at work. From the organisation, VETs expected (4) employment of strengths and (5) appreciation, trust, and autonomy.

VETs were enthusiastic about learning new and developing their work, their expertise, and themselves. Therefore, they also expected that their work would offer them change and new challenges that would maintain their enthusiasm. VETs also experienced a strong sense of expertise, that they considered important to share with each other and to learn from each other.

"I am a little crazy about indulging into new things. Being able to do something new, develop it. - - For example, if they said that let us do this for the next two years or let us work like this for the year, that is not my thing. I need it to change, develop and live, and it needs to have those new elements." (T12)

In addition, VETs described the sense of meaning at work. It was often related to one's own strong values and willingness to influence on matters important to oneself. The sense of meaning could be strengthened by appreciation and positive feedback. However, VETs reported that they received feedback mostly from students and other partners, rather than from their own organisation.

"I have these main principles of why I work with students. They will become good professionals and they know this job and they know themselves, have the knowledge of heart. Then I am able to lay down and sleep well." (T9)

VETs expected from their organisations that their strengths would be better noticed and employed at work. They realised that in order to fully keep up with the reform of vocational education, also VETs' strengths should be actively recognised.

"I think that we are increasingly going toward productivity, what is left below the line. - - To use core expertise and let those people really do who have the ability to do it." (T2) 
By focusing on individual attributes, VETs would have more autonomy at work, freedom to plan their teaching based on their strengths. This was considered a way of showing appreciation and trust by the organisation, too. However, also concrete rewards were also considered important elements of showing appreciation and increasing VETs' enthusiasm.

"So that not all work becomes too specified and maybe too limited." (T1)

"And that collaboration with work life. I have noticed that it is somehow really natural and easy for me and I feel that I get really much from it. So, that is something that I hope that would be noticed in that feedback. - - That is something I have been thinking about, that if your organisation does not react to it, it can really quickly make you cynical: 'why would I bother anymore?"' (T1)

\section{Deviant leadership}

Leadership and supervision were also seen crucial for enthusiasm: "That is the alpha and omega of it." (T5) From the data, four categories could be seen to describe this element of PRIDE: (1) leading daily work; (2) leading teacher enthusiasm; (3) leading strengths and potentials; and (4) leading emotions and work atmosphere.

Leaders' and supervisors' abilities to lead daily work were seen to be based on their interest in and understanding about VETs' professional fields and work. VETs appreciated their supervisors concrete experience of the field they were teaching, which made it possible to look for support from the supervisor if needed. Also the ability to provide feedback, encourage, and notice successes enhanced VETs' enthusiasm.

"The supervisor knows how this is, has been teaching too. The supervisor is a professional and has been actually working and therefore knows." (T13)

"If the management does not understand that their support is important to followers, we are lost. It is really important that the leaders appreciate each employee's effort and provide feedback on it." T6)

Enabling, renewing, and open-minded leadership was the key to leading enthusiasm, according to the VETs' opinion. They considered this kind of leadership also following the reform and making it possible to develop learning environments and pedagogy, and design innovative experiments and practices in vocational education. The reform could provide teachers with opportunities that necessitated supervisors "the courage, and when having more resources, giving them to us." (T2) Leaders can set the example of enthusiasm, too: "The supervisor is as if filled with energy and enthusiasm and new ideas like this." (T11)

VETs considered it important that leaders and supervisors employed strength-based approaches in leadership. They were expected to recognise VETs' potential, help them develop, and encourage toward professional growth and progress. According to VETs, this did not only strengthen their enthusiasm at work but commitment to the organisation too.

"Everyone is an individual and everyone has to be led in a way the person is." (T8)

"To lead so that this employee gets a chance to flourish in those areas that he or she finds motivating and strong for him or her." (T5)

"If I was a supervisor, I would be hearing it sensitively and also challenging by asking whether the employee wants to develop himself or the work and in which direction." (T1)

Those leaders and supervisors who were empathetic and people-oriented were regarded as able to lead emotions and the atmosphere at the workplace. This was shown in practice as the ability to discuss issues when sensing something was wrong, and to recognise and identity feelings at the workplace. Mainly, VETs found their own supervisors emotionally intelligent and easy to approach. However, it was evident in the interview data that supervisors could have quite different ways of working even within the same organisation. 
"Whenever needed, the supervisor intervenes. And listens. - - So, quite magnificently can handle these kinds of things without blaming anybody, but by discussing." (T4)

"You can see different leadership styles in our organisation. - - We have some department heads whose departments have totally different atmosphere, which is also visible outside." (T10)

\section{Emotional well-being}

The fifth element of PRIDE is emotional well-being, that according to Cheung's (2014) definition covers mental and physical well-being and positive emotions. In the data, three categories could be found to describe this element of PRIDE from the perspective of VETs' enthusiasm: (1) changes at work and related feelings of insecurity and being unaware; (2) atmosphere and its meaning in general; and (3) resources and coping at work.

VETs mainly described the change due to the present reform, and how it influenced their enthusiasm, well-being, and atmosphere at work. The reform had changed organisational structures and facilities that all changed daily work. In addition, the change in pedagogy was seen as burdening. All the feelings of uncertainty decreased VETs' enthusiasm.

"When you think about that teacher, we do have such unstable times that how can you become enthusiastic now." (T3)

Constant pressures to cut costs and lay off employees had a negative influence on atmosphere at work and caused stress. These also directly seemed to decrease VETs' enthusiasm.

"To have such huge national cuts in education and having all news telling how many VETs are unemployed and which organisation will lay off people next, it certainly creates a certain basic atmosphere." (T10)

"You can say that the atmosphere is even contradictory. The basic feeling of security that comes from having a permanent employment and related future views has been shaken for quite many of us." (T10)

\section{Discussion}

As the results showed, VETs were able to name factors related to all elements of PRIDE that influenced their enthusiasm at work. Based on the findings, PRIDE theory can be used for describing enthusiasm in VETs, because there were not any themes or categories that did not fit in the categories formed based on PRIDE. However, the original PRIDE is a quantitative index, developed in a different type of workplace and culture. Sub-categories formed in this research can be seen as professional specific elements of enthusiasm in VETs during the ongoing reform of vocational education (see also Bakker 2017).

The research also increased understanding about the dynamics of PRIDE: its elements are not equal, but it seemed in the context of vocational education that leadership influenced all categories, practices enhanced other categories, and various expectations could be set at leadership. Table 1 gives a summary of findings of how positive organisation and leadership can enable enthusiasm in teachers. 
Table 1. Elements of PRIDE and VETs' enthusiasm

\begin{tabular}{|c|c|}
\hline Element of PRIDE & Categories of Enthusiasm \\
\hline \multirow{3}{*}{$\begin{array}{l}\text { POSITIVE } \\
\text { PRACTICES }\end{array}$} & Practices enhancing development of work and professional growth \\
\hline & Practices enhancing interaction and collaboration \\
\hline & Practices enhancing efficient and quality pedagogical work \\
\hline \multirow{3}{*}{$\begin{array}{l}\text { RELATIONSHIP } \\
\text { ENHANCEMENT }\end{array}$} & Inspiring people and shared enthusiasm \\
\hline & Colloquial support \\
\hline & Enabled collaboration \\
\hline \multirow{5}{*}{$\begin{array}{l}\text { INDIVIDUAL } \\
\text { ATTRIBUTES }\end{array}$} & Personal development and opportunity develop work \\
\hline & Expertise usage and sharing \\
\hline & Sense of meaning at work \\
\hline & Employment of strengths \\
\hline & Appreciation, trust, and autonomy \\
\hline \multirow{4}{*}{$\begin{array}{l}\text { DEVIANT } \\
\text { LEADERSHIP }\end{array}$} & Leading the daily work \\
\hline & Leading teacher enthusiasm \\
\hline & Leading strengths and potentials \\
\hline & Leading emotions and work atmosphere \\
\hline \multirow{3}{*}{$\begin{array}{l}\text { EMOTIONAL } \\
\text { WELLBEING }\end{array}$} & Change-related emotions \\
\hline & Emotional atmosphere at workplace \\
\hline & Sufficiency of resources \\
\hline
\end{tabular}

When analysing the findings, it seemed evident that the elements of PRIDE were overlapping and reciprocal when viewed from the perspective of VETs' enthusiasm. Three themes appeared common to the elements of PRIDE in the data of this research, that can be named as the features of an organisation enhancing employee enthusiasm. Consequently, the following themes are not just based on VETs' perceptions but can be seen merely as the keys to enhance enthusiasm (cf., Meyer 2017):

(1) Opportunities for self-development and development of work,

(2) recognition and employment of strengths and potential, and

(3) enhancement of positive interaction and collaboration.

The original PRIDE (Cheung 2014) and the findings of this research differed from each other to some extent. For example, individual attributes in PRIDE cover widely the topic of employing characteristic strengths. Some strengths could be seen in this research data, too, such as creativity and optimism, but in this research, sub-categories to each element of PRIDE were formed in a data based manner. Likewise, the element of leadership was, in Cheung's (2014) index, the narrowest when compared to the other elements of PRIDE. However, our research brought up the significance of leadership more widely. It is also noteworthy that PRIDE was designed to measure positivity in an organisation and was to be used as a tool for a specific organisation in the field of social work (Cheung 2014). Based on our findings, PRIDE could be adopted in many kinds of institutions: here, we have highlighted themes important to enthusiasm in vocational education institutions. 
The themes support the findings of earlier research on VETs' enthusiasm (see Wenström et al. 2018). The conclusion is that enthusiasm can be enhanced and enabled through positive leadership and organisation of work. Positive organisation of work means "generative dynamics in and of organisations that enable individuals, groups, and organizations as a whole to flourish" (Fredrickson \& Dutton 2008). Furthermore, the findings showed that, as earlier studies have suggested (e.g., Bakker \& Demerouti 2014; Bakker, Van Veldhoven \& Xanthopoulou 2010; Harter \& Blacksmith 2013; Wenström et al. 2018), the opportunity to develop work and professional growth is an important factor of enthusiasm. Likewise, lack of these opportunities can lead to desire to change workplace (Harter \& Blacksmith 2013). This was also brought up by the research participants in this research, and emphasised development opportunities at the levels of practices, individual potentials, and leadership.

Secondly, this research supported the notion that the recognition and use of strengths have gained only little attention in education institutions (see also Bloom et al. 2015; Harter \& Blacksmith 2013). Finnish studies suggest that our vocational education institutions do not possess means to notice top performances or strengthen top workers' engagement (Jokinen, Sieppi \& Maliranta 2018). One reason might be that in education, work tasks have never before been designed according to teachers' strengths (cf., Bakker \& Demerouti 2014: Mroz \& Quinn 2013) nor have teachers been expected to advance in their careers (e.g. Bubb 2005). However, this research showed that enthusiastic VETs expect to have opportunities to expand their work contents, and to advance their careers within their own organisations. Best opportunities for this kind of usage of strengths were provided by various teamwork, projects, and networks.

According to the findings, enthusiasm emerges and strengthens in positive interaction. Indeed, collaboration can lead to a shared meaningful engagement and sense of energizing work (see Baker et al. 2003; Bakker et al. 2006; Geue 2018; Schippers \& Hogenes 2011; Sekerka \& Fredrickson 2013; Stairs \& Galpin 2013; Owens et al. 2016; Wenström et al. 2018). Enthusiastic VETs actively sought opportunities to work in positive energy networks (Baker et al. 2003; see also Gittell 2013; Owens et al. 2016). Moreover, the elements of enthusiasm reported in findings seemed to correspond to the requirements set for VETs in the educational reform: they are expected to work in a more collaborative, developing, and networking manner. Therefore, it would be crucial to pay attention to the development of flexible structures, practices, and organisation of work that would enhance interaction and collaboration in vocational education institutions (Baker \& Dutton 2007; Geue 2018; Reeves et al. 2017).

Positive leadership that enhances enthusiasm in VETs covered task support and emotional and relationship support (see also Cheung \& Wong 2011). In addition, positive leadership was expected to include managing of engagement and talent identification (Harter \& Blacksmith 2013). Although enthusiastic employees have been found to maintain and strengthen their own resources and engagement to some extent (Bakker \& Demerouti 2014) and develop self-feedback systems (Albrecht et al. 2015), this study showed that even enthusiastic VETs longed for feedback, appreciation, and rewards from successes from leaders and supervisors.

The reform of vocational education, not itself but the related cuts and lays-off, significantly seemed to decrease VETs' enthusiasm. The reform creates opportunities to use creativity and focus on strengths but also sets challenges that threaten teachers' enthusiasm and well-being at work (see also Day 2002; Vähäsantanen \& Eteläpelto 2011).

\section{Conclusion}

In educational institutions, analysis of leadership is especially significant because it also influences pedagogical work and students' performance (Bloom et al. 2015; Coelli \& Green 2012; Heck \& Hallinger 2010; Leithwood et al. 2008). And yet, the quality of leadership practices has been noted to vary more in schools than other work fields (Bloom et al. 2015). Indeed, human resource management is the weakest area of educational leadership internationally (Bloom et al. 2015; Jokinen et al. 2018). Positive leadership can be crucial to for example employee well-being (Kuoppala, Lamminpää, Liira \& Vainio 2008; Salmi, Perttula \& Syväjärvi 2014; Skakon, Nielsen, Borg \& Guzman 2010). In addition to 
well-being, good leader-follower interaction (Hulpia \& Devos 2010; Shier \& Graham 2011) and support from leaders and supervisors (Bakker et al. 2006) are important to enthusiasm and work engagement.

This research showed that the elements of PRIDE can be used for analysing how VETs perceive their enthusiasm at work, and thus expands the theory into new fields and perspectives. For example, instead of quantitative information, it is useful for research of human experiences and perceptions. The elements of PRIDE seemed interconnected and yet possible to view separately, too. This research provided further understanding about the concept and dynamics of positive organisations from the employees' perspective. Equally important was to point out how enthusiasm: as meaningful a resource it is, is inadequately noticed, recognised, and led in educational organisations (Owens et al. 2016; Saks 2017) According to this research, VETs' enthusiasm was best enabled by such positive leadership and organisation that supported development, paid attention to teachers' strengths, and promoted positive interaction and collaboration. Therefore, positive leadership and organisation make an important wellbeing factor (e.g., Salmi et al. 2014). Furthermore, by consciously leading enthusiasm, it is possible to support the development of teaching that is pursued by the reform of vocational education. This will enhance the quality and efficiency of education as well as teachers' ability to face and cope with the change. Enthusiastic, positive teachers are active agents of change (see also Lam et al. 2010; Macey \& Schneider 2008)! It would be important to connect factors promoting enthusiasm to the organizational strategies, processes, and systems (Albrecht et al. 2015; Guest 2014; Saks 2017; see also Thompson et al. 2015).

Educational organisations, as they are so massive, stiff, and hierarchical, may find leading enthusiasm challenging, because rigid structures are the main destroyers of creativity, innovation, and work engagement in teachers (Gittell 2012; Saks 2017). Therefore, it would be reasonable to critically evaluate the benefits of cuts and centralisation of educational units if these actions limit the conditions of enthusiasm (see also Day 2002). Moreover, as vocational educational teaching is changing, it should be discussed whether each teacher is expected to expand their expertise into new areas by developing their weaknesses, or whether they are provided with opportunities to better utilise their strengths and potential in collaborative teams and networks? When re-designing jobs (see also Bakker \& Demerouti 2014), would it be possible to do individually tailored work contents that would focus, for example, on student supervision and guidance, special needs support, or collaboration with workplaces in a way that would form core teams that are based on teachers' and other personnel's strengths and interests?

In this research, leadership and organisations were viewed from the perspective of VETs' enthusiasm. Because the core of positive organisations is leadership, the next step would be to analyse leaders' and supervisors' viewpoints of leadership that enhances VETs' enthusiasm (see also Coelli \& Green 2012). Hearing just teachers' perspectives does not provide the full picture. Likewise, the PRIDE theory would need further testing and validating in Finnish education institutions, to determine what kind of relation there is between the positive organisational index and quality and effectiveness scores of Finnish vocational education. This research provided a fresh, functional way of analysing enthusiasm in vocational education teachers. The core features of positive organisations and leadership highlighted here are hopefully useful and concrete tools to Finnish and international organisers of vocational education when considering the new educational arrangements and pursuing securing VETs' work engagement and well-being at work. 


\section{References}

Albrecht S.L., Bakker A.B., Gruman J.A., Macey W.H., \& Saks A.M. (2015). "Employee engagement, human resource management practices and competitive advantage: An integrated approach". Journal of Organizational Effectiveness: People and Performance, 2(1), 7-35.

Baker W., Cross R., \& Wooten M. (2003). "Positive organizational network analysis and energizing relationships." In Cameron K.S., Dutton J.E. \& Quinn R.E. (Eds.), Positive organizational scholarship: Foundations of a new discipline (pp. 328-342). San Francisco, CA: Berrett-Koehler.

Baker W. \& Dutton J.E. (2007). "Enabling positive social capital in organizations." In Dutton J.E., \& Ragins B.R. (Eds.), Exploring positive relationships at work. Building a theoretical and research foundation (pp. 325-345). London: Lawrence Erlbaum Associates.

Bakker A.B. (2017). "Strategic and proactive approaches to work engagement." Organizational Dynamics, 46(2), 67 - 75.

Bakker A.B., \& Demerouti E. (2014). "Job demands-resources theory". In Chen P.Y. \& Cooper C.L.(Eds.), “ (pp. 37-64). New York, NY: Wiley Blackwell.

Bakker, A. B., Van Emmerick, I. J. H., \& Euwema, M. C. (2006). "Crossover of burnout and enagement in work teams". Work and Occupations, 22, 464 - 489.

Bakker A.B., Van Veldhoven M.J.P.M., \& Xanthopoulou D. (2010). "Beyond the Demand-Control model: Thriving on high job demands and resources." Journal of Personnel Psychology, 9(1), 3-16.

Bakker, A. B., \& Bal, P. M. (2010). "A study among starting teachers." Journal of Occupational and Organizational Psychology, 83(1), 189-206.

Basit T. (2003). "Manual or electronic? The role of coding in qualitative data analysis." Educational Research, 45(2), 143-154.

Beverborg A.O.G., Sleegers P.J.C., \& van Veen, K. (2015). "Fostering teacher learning in VET colleges: Do leadership and teamwork matter?" Teaching and Tacher Education, 48, 22-33.

Biswas-Diener R., Kashdan T.B., \& Minhas G. (2011). "A dynamic approach to psychological strength development and intervention." The Journal of Positive Psychology, 6(2), 106-118.

Bloom N., Lemos R., Sadun R. \& Van Reenen J. (2015). "Does management matter in schools?" Economic Journal, 125, 647-674.

Bubb S. (2005). Helping teachers develop. Thousand Oaks, CA: SAGE.

Cameron K.S. (2008). "Paradox in positive organizational change." Journal of Applied Behavioral Science, 44(1), 7-24.

Cameron K.S. (2012). Positive leadership. Strategies for extraordinary performance. Second edition. Oakland, CA: Berrett-Koehler.

Cameron, K.S. (2013). "Advances in positive organizational scholarship". Advances in Positive Organizational Psychology, 1, 22-44.

Cameron K., Mora C., Leutscher T., \& Calarco M. (2011). "Effects of positive practices on organizational effectiveness". The Journal of Applied Behavioral Science, 47(3), 266-308.

Cheung R.K.H. (2014). "An ethnographic case study on transformation of a social welfare agency into a positive organization". The Hong Kong Polytechnic University.

Retrieved from: http://ira.lib.polyu.edu.hk/handle/10397/35451

Cheung R.K.H. (2015) "Positive workplaces in Hon Kong: Building positive organizations, engaging the heart of employees". In Lopez S.J., Pedrotti J.T. \& Snyders C.R. (Eds.), Positive psychology: The scientific and practical explorations of human strengths (pp. 450-453). Thousand Oaks, CA: Sage. 
Cheung M.F.Y., \& Wong C. (2011). "Transformational leadership, leader support and employee creativity." Leadership \& Organizational Development Journal, 32(7), 656-672.

Coates H., Meek L., Brown J., Friedman T., Noonan P., \& Mitchell J. (2013). "VET leadership for the future - characteristics, contexts and capabilities". Journal of Further and Higher Education, 37(6), 819-843.

Coelli M., \& Green D.A. (2012). "Leadership effects: school principals and student outcomes". Economics of Education Review, 31(1), 92-109.

Cozby P.C. \& Bates S.C. (2012). Methods in behavioral research. (11th ed.) New York, NY: McGrawHill.

Creswell J.W. (2014). Research design. International student edition. Qualitative, quantitative and mixed methods approaches. London: Sage.

Creswell J.W., \& Miller D.L. (2000). "Determining validity in qualitative inquiry." Theory into practice, 39(3), 124-130.

Davis J.S. (2013). "Building the positive workplace: A preliminary report from the field." In Linley P.A., Harrington S. \& Garcea N. (Eds.), The Oxford handbook of positive psychology and work (pp. 289-298). New York, NY: Oxford University Press.

Day C. (2002). "School reform and transitions in teacher professionalism and identity." International Journal of Educational Research, 37(8), 677-692.

Demerouti E., \& Cropanzano R. (2010). "From thought to action: employee work engagement and job performance." In Bakker A.B. \& Leiter M.P. (Eds.), Work engagement: a handbook of essential theory and research (pp. 147-163). New York, NY: Psychology Press.

Doldor E., Silvester J., \& Atewologun D. (2017). In Rogers W.S., \& Willig C. (Eds.). "Qualitative methods in organizational psychology." In The SAGE handbook of qualitative research in psychology (pp. 520-540). London: Sage.

Francis J.J., Johnston M., Robertson C., Glidewell L., Entwistle V., Eccles M.P. \& Grimshaw J.M. (2010). "What is an adequate sample size? Operationalising data saturation for theory-based interview studies." Psychology \& Health, 25(10), 1229-1245.

Fredrickson B.L., \& Dutton J.E. (2008). "Unpacking positive organizing: Organizations as sites of individual and group flourishing." The Journal of Positive Psychology, 3(1), 1-3.

Fredrickson B.L. \& Joiner J. (2002). "Positive emotions trigger upward spirals toward emotional wellbeing." Psychological Science, 13(2), 172-175.

Frenzel A.C., Goetz T., Lüdtke O., Pekrun R. \& Sutton R.E. (2009). "Emotional transmission in the classroom: exploring the relationship between teacher and student enjoyment." Journal of Educational Psychology, 101(3), 705-716.

Galletta A. (2012). Mastering the semi-structured interview and beyond: from research design to analysis and publication. New York, NY: NYU Press.

Geue PE. (2018). "Positive practices in the workplace: impact on team climate, work engagement, and task performance". The Journal of Applied Behavioral Science, article first published online: May 11, 2018, doi: $10.1177 / 0021886318773459$

Gittell J. H. (2012). "New directions for relational coordination theory" In Cameron K.S. \& Spreitzer G.M. (Eds.), The Oxford handbook of positive organizational scholarship (pp. 400-411). New York, NY: Oxford University Press.

Gittell J., Seidner R. \& Wimbush J. (2010). “A relational model of how high-performance work systems work.” Organization Science, 21(2), 490-506. 
Gruman J.A., \& Saks A.M. (2011). "Performance management and employee engagement." Human Resource Management Review, 21, 123-136.

Guest D.E. (2014). "Employee engagement: a skeptical analysis." Journal of Organizational Effectiveness: People and Performance, 1(2), 141-156.

Hartel, C.E.J. \& Ashkanasy N.M. (2011). "Healthy human cultures as positive work environments. "In Ashkanasy N.M., Wilderom C.P.M. \& Peterson M.F. (Eds.), The handbook of organizational culture and climate (pp. 85-100). Thousand Oaks, CA: Sage.

Harter J.K., \& Blacksmith N. (2013). "Employee engagement in the psychology of joining, staying in and leaving organizations." In Linley P.A., Harrington S., \& Garcea N. (Eds.), The Oxford handbook of positive psychology and work (pp. 121-130). New York, NY: Oxford University Press, 121 - 130.

Heck R. H. \& Hallinger P. (2010) "Testing a longitudinal model of distributed leadership effects on school improvement”. , 21, 867-885.

Hsieh, H. F., \& Shannon, S. E. (2005). "Three approaches to qualitative content analysis". Qualitative Health Research, 15(9), 1277-1288.

Hulpia H., \& Devos G. (2010). "How distributed leadership can make a difference in teachers' organizational commitment? A qualitative study." Teaching and Teacher Education, 26(3), 565-575.

Ince C.E., Jelley R.B. \& MacKinnon S.L. (2016). "Leadership's effects on employee well-being: synthesizing the qualitative evidence." Workplace Review, April 2016, 3-18.

Jokinen J., Sieppi A., \& Maliranta M. (2018). "Johtamiskäytäntöjen laatu Suomen ammatillisessa peruskoulutuksessa" [The quality of leadership practices in the Finnish vocational education]. Kansantalouden aikakauskirja, 114(2). Retrieved from: http://www.taloustieteellinenyhdistys.fi/wpcontent/uploads/2018/05/KAK_2_2018_WEB-10-23.pdf

Jäppinen A.-K., \& Maunonen-Eskelinen I. (2012). "Organisational transition challenges in the Finnish vocational education - perspective of distributed pedagogical leadership." Educational Studies, 38(1), $39-50$.

Keller M.M., Neumann K., \& Fischer H.E. (2013). "Teacher enthusiasm and student achievement.” In Hattie J. \& Anderman J.M. (Eds.). Educational psychology handbook: international guide to student achievement (pp. 247-250). London: Routledge.

Kunter M., Frenzel A.C., Nagy G., Baumert J., \& Pekrun R. (2011). "Teacher enthusiasm: dimensionality and context specificity." Contemporary Educational Psychology, 36, 289-301.

Kunter M., \& Holzberger D. (2014). "Loving teaching: Research on teachers' intrinsic orientations.” In Richardson P.W., Karabenick S.., \& Watt H.M.G.(Eds.), Teacher motivation: Theory and practice (pp. 83-99). New York, NY.: Routledge.

Kunter M., Klusmann U., Baumert,J., Richter D., Voss T., \& Hachfeld. A. (2013). "Professional competence of teachers: effects on instructional quality and student development." Journal of Educational Psychology, 105(3), 805-820.

Kuoppala, J., Lamminpää, A., Liira, J., \& Vainio, H. (2008). "Leadership, job well-being, and health effects-A systematic review and a meta-analysis". Journal of Occupational and Environmental Medicine, 50(8), 904-915

Lam S., Cheng R.W., \& Choy H.C. (2010). "School support and teacher motivation to implement project-based learning." Learning and Instruction, 20(6), 487-497.

Leithwood K., Harris A., \& Hopkins D. (2008). "Seven strong claims about successful school leadership". School Leadership and Management, 28(1), 27-42.

Linley P.A., Harrington S., \& Garcea, N. (2013). "Finding the positive in the world of work." In Linley P.A., Harrington S., \& Garcea N. (Eds.) The Oxford handbook of positive psychology and work (pp. 39). New York, NY: Oxford University Press. 
Macey W.H., \& Schneider B. (2008). "The meaning of employee engagement." Industrial and Organizational Psychology, 1(1), 3-30.

Meyer J.P. (2017). "Has engagement had its day: What's next and does it matter?" Organizational Dynamics, 46(2), 87 - 95.

Minedu (2017). "Vocational education and training reform approved - the most extensive education reform in decades". Press release 1.8.2017. Finnish Ministry of Education and Culture. Retrieved from: https://minedu.fi/en/article/-/asset_publisher/ammatillisen-koulutuksen-reformi-hyvaksyttiin-suurinkoulutusuudistus-vuosikymmeniin

Mroz D., \& Quinn S. (2013) "Positive organizational scholarship leaps into the world of work". In Linley P.A., Harrington S. \& Garcea N. (Eds.), The Oxford handbook of positive psychology and work (pp. 251 - 264). New York, NY: Oxford University Press.

Määttä, K., \& Uusiautti, S. (2018). The psychology of study success in universities. New York, NY: Routledge.

Ong A.D., Bergeman C.S., Bisconti T.L., \& Wallace K.A. (2006). "Psychological resilience, positive emotions and successful adaptation to stress in later life." Journal of Personality and Social Psychology, 91(4), 730-749.

Oades L.G., Robinson P., Green S., \& Spence G.B. (2011). “Towards a positive university.” Journal of Positive Psychology, 6(6), 432-439.

Owens B.P., Baker W.E, McDaniel Sumpter D. \& Cameron K.S. (2016). "Relational energy at work: implications for job engagement and job performance." Journal of Applied Psychology, 101(1), 35-49.

Patrick B.C., Hisley, J. \& Kempler, T., (2000). ""What's everybody so excited about?": The effects of teacher enthusiasm on student intrinsic motivation and vitality." Journal of Experimental Education, 68(3), 217-236.

Peräkylä, A. (2011). Validity in research on naturally occuring social interaction. In D. Silvermann (Ed.), Qualitative research. Issues of theory, method and practice (pp. 365 - 382). London: Sage.

Reeves P.M., Pun W.H. \& Chung K.S. (2017). "Influence of teacher collaboration on job satisfaction and student achievement." Teaching and Teacher Education, 67, 227-236.

Richardson J., \& West M.A. (2013). "Dream teams: A positive psychology of team working." In Linley P.A, Harrington S., \& Garcea N. (Eds.), The Oxford handbook of positive psychology and work (pp. 235-249). New York, NY: Oxford University Press.

Rich G.J. (2016) "The promise of qualitative inquiry for positive psychology: Diversifying methods." The Journal of Positive Psychology, 12(3), 220-231.

Saks A.M. (2017). "Translating employee engagement research into practice." Organizational Dynamics, 46(2), 76-86.

Salanova, M., Bakker, A.B. \& Llorens, S. (2006). Flow at work: Evidence for a gain spiral of personal and organizational resourcess, 7(1), $1-22$.

Salmi I.,Perttula J. \& Syväjärvi A. (2014). "Positive leadership and experiences explaining workers' well-being in knowledge-intensive organization". The Polar Journal, 4, 52-68.

Schaufeli W.B. (2018). "Work engagement in Europe: Relations with national economy, governance and culture." Organizational Dynamics, 47(2), 99-106.

Schaufeli W.B., Salanova M., González-Romá V., \& Bakker A.B. (2002). "The measurement of engagement and burnout: A two sample confirmatory factor analytic approach". Journal of Happiness Studies, 3(1), 71-92.

Schippers M.C., \& Hogenes R. (2011). "Energy management of people in organizations: A review and research agenda". Journal of Business and Psychology, 26(2), 193 - 203. 
Sekerka L.E., \& Fredrickson B.L. (2013). "Working positively toward transformative co-operation.” In Linley P.A, Harrington S. \& Garcea N. (Eds.), The Oxford handbook of positive psychology and work (pp. 81 - 94). New York, NY: Oxford University Press.

Shier, M.L., \& Graham, J. R. (2011). "Work-related factors that impact social work practitioners' subjective well-being.: Well-being in the workplace". Journal of Social Work, 11(4), 402-421.

Skakon, J., Nielsen, K., Borg, V., \& Guzman, J. (2010). "Are leaders' well-being, behaviours and style associated with the affective well-being of their employees? A systematic review of three decades of research.” Work \& Stress, 24(2), 107-139.

Stairs M. \& Galpin M. (2013). "Positive engagement: From employee engagement to workplace happiness". In Linley P.A., Harrington S. \& Garcea N. (Eds.), The Oxford handbook of positive psychology and work (pp. 155-172). New York, NY: Oxford University Press.

Steger M.F., \& Dik B.J. (2013). "Work as meaning: Individual and organizational benefits of engaging in meaningful work." In Linley P.A., Harrington S. \& Garcea N. (Eds.), The Oxford handbook of positive psychology and work (pp. 131 - 142). New York, NY: Oxford University Press.

Thompson K.R., Lemmon G., \& Walter T.J. (2015). "Employee Engagement and Positive Psychological Capital." Organizational Dynamics, 44(3), 185-195.

Thoonen E.E.J., Sleegers P.J.C., Oort F.J., Peetsma, T.T.D. \& Geijsel, F.P. (2011). "How to improve teaching practices: The role of teacher motivation, organizational factors, and leadership practices". Educational Administration Quarterly, 47(3), 496-536.

Uusiautti, S. (2016). Success at work requires hope and the ability to engage in an optimistic attitude. European Journal of Workplace Innovation, 2(2), 41-64.

Wenström, S., Uusiautti, S., \& Määttä, K. (2018, in press). “The force that keeps you going”. Enthusiasm in vocational education and training (VET) teachers' work. International Journal for Research in Vocational Education and Training.

Vähäsantanen K., \& Eteläpelto A. (2011). "Vocational teachers' pathways in the course of a curriculum reform." Journal of Curriculum Studies, 43(3), 291-312.

Vähäsantanen K., Saarinen J., \& Eteläpelto A. (2010). "Between school and working life: Vocational teachers' agency in boundary-crossing settings." International Journal of Educational Research, 48, $395-404$.

Xanthopoulou D., Bakker A B., Demerouti,E., \& Schaufeli W.B. (2009). "Work engagement and financial returns: A diary study on the role of job and personal resources". Journal of Occupational and Organizational Psychology, 82, 183-200.

\section{About the authors:}

Sanna Wenström, MA, M.Phi., a vocational special education teacher, is a $\mathrm{PhD}$ student at the University of Lapland, Finland. She works in the development of vocational education teachers and supervisors.

Satu Uusiautti, $\mathrm{PhD}$, is a professor of education, especially educational psychology at the University of Lapland, Finland.

Kaarina Määttä, $\mathrm{PhD}$, is a professor of educational psychology and vice-rector of the University of Lapland, Finland. 